\title{
Os blogs não são diários pessoais online: matriz para a tipificação da blogosfera
}

\begin{abstract}
RESUMO
Blogs foram inicialmente definidos como diários íntimos online. Diante de tal visão reducionista, e após discutir a heterogeneidade da blogosfera - incluindo blogs organizacionais, educacionais, splogs, flogs e o caráter público ou privado dessas publicações - , este artigo apresenta uma matriz para a tipificação de blogs. A partir de uma reflexão de diversas dimensões de estudo, propõe-se quatro grandes grupos: pessoal e profissional (blogs individuais); grupal e organizacional (coletivos).
\end{abstract}

\section{PALAVRAS-CHAVE \\ $b \log$ \\ blogosfera \\ interação}

\section{ABSTRACT}

Blogs were initially defined as online intimate journals. Facing such a reductionist vison, and after discussing the blogosphere's heterogeneity - including organizational and educational blogs, splogs, flogs and the public or private character of these publications - , this paper presents a matrix for typifying blogs. Based on some analytical dimensions, four groups are proposed: personal and professional (individual blogs); group and organizational (colective).

\section{KEY WORDS}

blog

blogosphere

interaction
Diante da popularização dos blogs, buscou-se logo encontrar um meio ou gênero anterior que oferecesse pistas explicativas para a compreensão daquela nova modalidade de escrita. A comparação com diários pessoais ${ }^{1}$ encontrou consenso com rapidez.

Apesar de sabermos que novos meios "remediam" meios anteriores (Bolter, 2001), diários pessoais e blogs apresentam características muito distintas que prejudicam sua equiparação. Sim, ambos são formas de registro escrito que seguem uma explícita organização cronológica. Uma parcela de blogs de fato baseia-se na escrita de percepções e reflexões sobre o cotidiano e os sentimentos do autor. Contudo, essa prática não se aplica a tantos outros blogs, que apresentam estilos e objetivos diversos. A principal distinção entre diários e blogs os opõem de maneira inconciliável. Diários pessoais se voltam para o intrapessoal, tem como destinatário o próprio autor. Blogs, por outro lado, visam o interpessoal, o grupal.

Nardi, Schiano e Gumbrecht (2004) lembram que saudações, conselhos e convites, normais em blogs, são ações sociais e jamais apareceriam em diários tradicionais. " $\mathrm{O}$ blog não é um mundo fechado, mas parte de um espaço comunicacional maior no qual vários meios, e comunicação face a face, também podem ser usados. Blogs, portanto, se diferem de diários privados, sendo de natureza totalmente social" ${ }^{2}$ (p. 225).

Como se verá adiante, nem todo blog é aberto a qualquer leitor. Algumas empresas e grupos de trabalho/ pesquisa mantém blogs em intranets ou protegidos por senhas. Estes exemplares são escritos para o compartilhamento e debate de informações, ainda que em um círculo fechado. Nestes casos, o blog é também produzido para ser lido por outros.

De fato, pode-se utilizar o sistema de publicação de blogs como bloco de notas (para se guardar idéias e links para informações de interesse pessoal) e, sim, como repositório de reflexões e criações literárias inacabadas. Contudo, o uso da interface de blogs para a escrita íntima e sigilosa é apenas um entre tantos processos interativos possíveis na blogosfera. Logo, definir-se blogs como diário íntimo online ou mesmo como página pessoal (o que excluiria as produções grupais e organizacionais) é capciosa e reducionista.

É interessante observar que ninguém ousaria definir categoricamente que o suporte papel é jornalismo, ou que seu conteúdo é superficial. Tampouco seria correto insistir que rádios FM apenas tocam músicas e rádios AM veiculam tão somente jornalismo, nem que emissoras de televisão sejam sinônimo de novelas. Por outro

\author{
Alex Primo \\ Professore e vice-coordenador do Programa de Pós-Graduação em \\ Comunicação e Informação da UFRGS/RS/BR \\ aprimo@ufrgs.br
}


lado, com grande facilidade concorda-se que blogs são diários pessoais, escritos em tom confessional, recheados de banalidades. É importante desconfiar de analogias e metáforas, buscando avaliar seus alcances, já que elas não apenas salientam certos aspectos, como também escondem outros ${ }^{3}$.

Mas por que se insiste em definir o conteúdo de um blog em virtude do uso da ferramenta? Minha hipótese é que o uso do termo "blog" com 3 conotações diferentes é em grande medida responsável por tal confusão. Conforme discuti em outro lugar (Primo e Smaniotto, 2006b), a palavra "blog" designa não apenas um texto, mas também um programa e um espaço. Para simplificar esta discussão, apresento a seguir exemplos dos diferentes usos do mesmo termo:

1. como programa: "Parei de usar o Blogger. Instalei o Wordpress";

2. como espaço: "Não encontrei seu blog no Google. Qual o endereço dele?";

3. como texto: “Li ontem o seu blog e gostei do que você escreveu".

Da confusão entre blog/ programa e blog/texto decorre boa parte dos estereótipos sobre esse fenômeno da cibercultura. É preciso que fique claro que um blog/ programa não determina que o blog/texto deverá seguir um gênero específico. Deve ficar claro que blogs são muito mais que uma simples interface facilitada para a publicação individual, como são freqüentemente definidos. Faço tal alerta não apenas para criticar uma definição que se resume à descrição do meio, mas também para lembrar que blogs são espaços coletivos de interação. Ou seja, blogs/espaço podem converter-se em um ponto de encontro. Tem razão De Kerckhove quando afirma: "Não creio que seja uma exibição do eu, mas antes da relação com os outros" ${ }^{\prime 4}$. Como a maior parte dos posts apresenta um link para o serviço de comentários, tal apontador funciona como um convite para a conversação. A observação empírica das conversações em blogs não é trivial, por utilizarem apenas a escrita, ocorrerem de forma assíncrona e por vezes "escorrerem" para outros blogs e interfaces de comunicação ${ }^{5}$.

Para que se possa avançar na crítica à definição prototípica de blogs como diários íntimos online, como interfaces para a auto-reflexão, de produção individual e "verdadeira", é importante estudar o uso estratégico dessas interfaces na contemporaneidade.

\section{Blogs organizacionais, blogs privados, splogs e flogs}

Muito distante das primeiras definições românticas ("a autencidade e a verdade dos blogs nos salvará da mídia de massa, capitalista e mentirosa") e normativas ("blogs devem/deveriam checar suas fontes, utilizar texto formal e evitar o humor e assuntos banais") ${ }^{6}$, os blogs passam a ser usados como recursos estratégicos em grandes organizações. Como ferramenta de comunicação organizacional, observa-se um caminho em sentido con- trário à idéia de que posts são uma forma de escrita espontânea e confessional. Usados nesses contextos por equipes de trabalho e ambientes científicos e educacionais de forma privada, cai também a defesa de que blogs são uma interface para a expressão pública e global.

Cada vez mais as empresas reconhecem a necessidade de administrar a imagem que têm diante de seus diversos públicos. Os blogs oferecem uma interface para o contato direto com funcionários, fornecedores, consumidores, acionistas, etc, além de servirem como importante fonte de informação para a imprensa. Esta é a defesa de Scoble e Israel (2006) para o que vêm sendo chamado de marketing conversacional.

De acordo com esses autores, a importância dos blogs para as organizações vêm do fato de que eles permitem que as conversações se tornem globais e que a comunicação corporativa seja descentralizada. Mas o aspecto mais importante de blogs, segundo os autores, é que eles facilitam a conversação. Ainda que reuniões presenciais sejam incomparáveis, os negócios globais inviabilizam os encontros com todos consumidores e investidores. Mesmo que outras tecnologias possam mediar diálogos, os blogs facilitam os debates grupais a partir de qualquer computador com acesso à internet.

Uma das principais razões para a importância dos blogs no contexto organizacional vem de sua relação custo/benefício: pode-se alcançar um público bastante grande com baixo investimento. Com relação ao seu alcance, os autores lembram que blogs são facilmente achados em mecanismos de busca, já que são atualizados com muito mais freqüência que o site institucional. As informações e contatos mantidos em blogs vinculados a empresas freqüentemente rendem posts e comentários em outros blogs, o que resulta em propaganda gratuita. A defesa de consumidores de bens, serviços e da própria instituição adquire grande força promocional pois diferencia-se de uma informação oficial. Scoble e Israel defendem que a conversação em blogs contribui para a construção de confiança, além de "humanizar" a empresa diante de seus públicos: "Blogs oferecerem o primeiro conjunto de ferramentas adequado para que executivos e homens de negócios possam passar suas mensagens diretamente a suas audiências - e que escutem seu retorno, algo que não acontece através da mídia ou outros mecanismos de transmissão ${ }^{7 \prime \prime}$ (Scoble and Israel, 2006, p. 48).

Enquanto algumas empresas motivam seus funcionários a publicarem blogs públicos (é o caso da Microsoft), em outras, como na Sun Microsystems, o próprio presidente da corporação mantém seu blog. De acordo com Scoble and Israel, tal blog é muito respeitado na área, até mesmo entre seus concorrentes, o que confere ainda maior credibilidade para a Sun. O interesse em desviar da imprensa, tendo total controle sobre as informações, é outra motivação para a criação de blogs de funcionários e executivos. Conforme aqueles autores, a invenção do recurso RSS por Dave Winer, CEO da companhia de 
software UserLand, teve como motivação o objetivo de divulgar informações da empresa diretamente.

O argumento de que blogs permitem a divulgação sem intermediações a partir da própria fonte aproxima-se dos discursos em defesa do jornalismo participativo (grassroots journalism, jornalismo open-source, jornalismo cidadão). No contexto organizacional, esse pressuposto vem acompanhado de força retórica. Como se sabe, não existe um acesso direto à verdade verdadeira, o fato cru. O que uma organização divulga em seus blogs corporativos tampouco escapa a qualquer mediação (ora, as informações não existem soltas no ar, livres dos meios, suas linguagens e das intenções dos produtores). Os posts são moldados na fôrma das estratégias, concretizados em palavras e imagens planejadas, visando certos efeitos. Os posts do blog do orkut ${ }^{8}$, por exemplo, são assinados por membros da equipe de produção daquela rede de relacionamentos. A linguagem informal, típica de muitos blogs, não é marca de um texto espontâneo, publicado diretamente sem revisão. Pelo contrário, trata-se de um texto promocional, muito bem formatado, que cumpre a expectativa de divulgação de novidades no sistema e convida a experimentação. Este blog é uma forma contemporânea de divulgação de press-releases, mas que utiliza uma linguagem e um meio muito bem identificado com o público jovem do sistema. Este blog, promove o que Scoble e Israel chamam de "humanização" da empresa e seus funcionários. A imagem que se passa, ou se pretende fazer crer, é que o público está em contato direto com os programadores do sistema.

Mas nem todos blogs organizacionais são públicos. Muitos deles são privados, voltados para o desenvolvimento de projetos estratégicos e novos produtos, como também para tornar o que se chama de conhecimento tácito em uma empresa em conhecimento explícito (Nonaka e Takeuchi, 1997). Este método que facilita o compartilhamento de know-how na empresa, como também a rápida a entrada e atualização de novos membros nas equipes. Na IBM, 3000 blogs são usados internamente para a cooperação de equipes. Outro uso de blogs privados é a substituição das chamadas "cartas do presidente". Conforme Scoble and Israel (2006), o CEO da Intel, Paul Otelli, mantém o Paul's Blog para se comunicar com os 86 mil funcionários da empresa.

Alguns blogs voltados para a educação, disponíveis em ambientes de educação a distância, também são fechados para acesso externo. Este método, comumente chamado de "diário de bordo", serve para o acompanhamento do professor, para o desenvolvimento de atividades em grupo e para os educandos tomarem consciência de sua própria evolução. Outros blogs coletivos, como de equipes científicas e de designers de produtos, são igualmente privados por tratarem de assuntos que exigem sigilo.

Estes dados nos mostram mais uma vez a limitação das definições românticas, que defendem que blogs são uma forma de se mostrar, de tornar público opiniões livres sobre qualquer tema, de necessária repercussão na identidade do autor, que busca uma conversação aberta com qualquer leitor, conhecido ou não. Diferentemente de páginas pessoais, muitos blogs organizacionais adotam uma linguagem impessoal, são redigidos por diferentes profissionais em cargo da tarefa. A rigor, pouco importam as crenças do redator profissional e quem seja ele (se é a mesma pessoa que sempre escreve, se uma equipe se reveza na redação; se trata-se de alguém experiente no ofício ou de estagiário que acaba de assumir a tarefa). O que vale nestes blogs corporativos impessoais, e muitos deles sequer oferecem a interface para comentários, é o posicionamento da empresa. Ou seja, este exemplar afasta-se sobremaneira da definição dos textos íntimos, de fortes marcas identitárias, das definições que igualam blogs a diários íntimos. Ainda que os românticos possam preferir responder que blogs organizacionais não são blogs, não se pode definir um meio, qualquer que seja ele, por seu conteúdo.

Se já não se pode mais definir blogs por seu caráter público, por algum gênero discursivo específico, nem como produção individual, tampouco se pode reverenciar a produção na blogosfera como definitivamente autêntica e verdadeira.

A visão idealista sobre o "conteúdo gerado pelos usuários" (user-generated content), recorrente nos textos sobre a Web 2.0, é duramente criticada por Keen (2007). Tal perspectiva é chamada pelo autor de "culto ao amador". Quanto aos blogs, Keen observa que informações falsas, difamatórias e dissimuladas (conteúdo publicitário disfarçado de notícia ou testemunhal) circulam com excessiva facilidade na rede, tendo em vista a proteção oferecida pelo anonimato e pseudônimos.

Contra uma possível inocência do blogs, Keen mira os chamados splogs e flogs. O primeiro tipo é uma combinação de spam e blog. Os splogs ${ }^{9}$ são criados em grande quantidade e de forma automatizada. Através de um algoritmo, reúne conteúdo de outros blogs, visando atrair tráfego para os anúncios publicitários lá publicados. Os splogs são usados para a subversão do sistema de mecanismos de busca e links patrocinados (como o Google AdSense). Já os floggers (fake bloggers ${ }^{10}$ se fazem passar por blogueiros independentes, mas na verdade escrevem sobre a regência de um ou mais anunciantes. Flogs podem ser financiados por uma instituição, apontando todo seu conteúdo para o ataque de concorrentes. Outro modelo mercadológico que colocaria sob suspeita a credibilidade de blogs, segundo Keen, é a escrita de posts dissimulados sobre produtos. A empresa PayPerPost.com sofisticou este processo, fazendo a mediação entre anunciantes e blogueiros. Quando um post submetido ao PayPerPost sobre um produto listado no sistema é aprovado, o blogueiro recebe de 5 a milhares de dólares ${ }^{11}$.

Diferentemente do que Keen quer fazer crer, blogs não são uma ameaça a jornalistas e outros profissionais que lidam com informações e texto. Hoje, boa parte dos sites 
de jornais, por exemplo, mantém diversos blogs de seus jornalistas contratados. Ou seja, blogs não podem ser vinculados, como pretende Keen, a uma produção amadora, descompromissada com fontes e fatos e despreocupada com processos legais.

Por trás das críticas desse autor, encontra-se uma visão normativa, que quer prescrever como os blogs deveriam ser e não como a blogosfera é. Contudo, as interações em blogs constituem um fenômeno social emergente, em constante mutação, que escapa a qualquer intenção normatizadora.

\section{Dimensões para a tipificação de blogs}

Diversas são as tipologias que buscam descriminar os blogs em grandes grupos. Contudo, a popularização desse serviço e a multiplicação de estilos e objetivos na blogosfera vêm causando dificuldades à aplicação das categorias propostas. Outra problema é o fato de que em um mesmo blog pode-se encontrar diversos gêneros dispersos em posts diferentes. Dessa forma, para que se possa avaliar um blog, buscando suas regularidades, é preciso avaliar uma amostra de posts significativa, e não apenas observar sua descrição e seu título. O que se apresenta a seguir é um conjunto de elementos e dimensões a serem avaliados em estudos que busquem observar blogs quanto ao seu gênero, temática, processo produtivo, etc. A discussão vindoura parte inicialmente da tipologia de Krishnamurthy (2002, citado por Herring, 2005), que avalia duas dimensões: pessoal $X$ temático, individual X comunidade (FIG. 1).

Figura 1 - Tipos de blogs

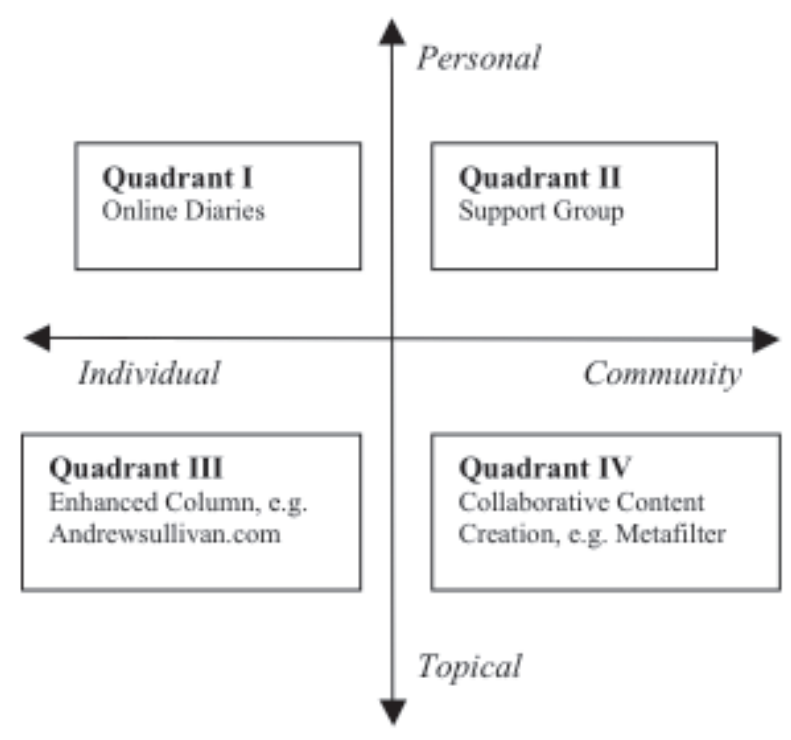

Fonte - Krishnamurthy (2002), citado por Herring (2004, p. 3).
A partir desse modelo, Herring (2005) propõe uma tipificação de blogs em 5 categorias: diário pessoal, filtro (comentários sobre atualidades), K-log (registro e observações sobre um domínio do conhecimento), misto ( $m i-$ xed) e outros. Apesar dos referidos modelos chamarem a atenção para importantes características ${ }^{12}$, as categorias propostas não são suficientes para o estudo para a grande variedade atual de blogs. As duas dimensões de análise de Krishnamurthy de fato devem ser consideradas no estudo de blogs. Entretanto, ficam de fora outros elementos que demandam atenção.

A re-elaboração de Herring trabalha com 3 tipos básicos (diário pessoal, filtro e K-log), que se negam mutuamente. $O$ restante recai em grandes categorias não diferenciadas (misto e outros). Os 3 primeiros tipos exigem um padrão específico, o que não abre margem para a experimentação e variedade. Os outros dois tipos, pela grande indiferenciação em seu interior, prejudicam justamente o reconhecimento da heterogeneidade da blogosfera. Como existe uma grande quantidade de blogs que exercita diferentes gêneros discursivos em diferentes posts (ou mesmo em um único post) e como o blogar vai sendo modificado com o tempo (tendo em vista a interação com a audiência, como também os humores e interesses dos blogueiros) é preciso buscar um método que reconheça o que é heterogêneo, mas que não o prenda em gavetas homogeneizadoras. Nesse sentido, as categorias "misto" e "outros" não são úteis para o fim proposto pela autora (a tipificação de blogs), pois aperta a textura da diferença em categorias planas.

Diante dessa demanda, este artigo apresentará uma nova proposta para o estudo de blogs. Alerto, porém, que não pretendo apresentar uma nova tipologia, mas sim um conjunto de dimensões que deve ser considerado na elaboração de modelos para a tipificação de blogs em categorias.

Em um primeiro momento, e antes de qualquer análise sobre o conteúdo dos posts, é preciso avaliar se o blog é produzido individualmente ou de forma coletiva. Ou seja, deve-se observar quem é responsável pela publicação e que condicionamentos daí decorrem. Blogs individuais podem ser subdivididos em pessoais e profissionais. Um blog coletivo pode ser grupal ou organizacional.

A criação de um blog pessoal é bastante simplificada. Não depende da avaliação de terceiros, como em um blog coletivo. Enquanto um blog profissional parte da delimitação de uma estratégia e dos interesses da instituição que o veicula, um blog pessoal depende tão somente da vontade de criá-lo. Assume-se um compromisso apenas com a audiência, que é a única que pode reclamar por atualizações e discutir os posts. O conteúdo e a periodicidade de um blog profissional, apesar de ser produzido por uma única pessoa, respondem a um objetivo comercial ou até mesmo para criar uma reputação em um determinado ramo, visando ganhos futuros, como contratos de consultoria.

Os blogs dos chamados "probloggers", mesmo que 
Figura 2 - Matriz para tipificação de blogs

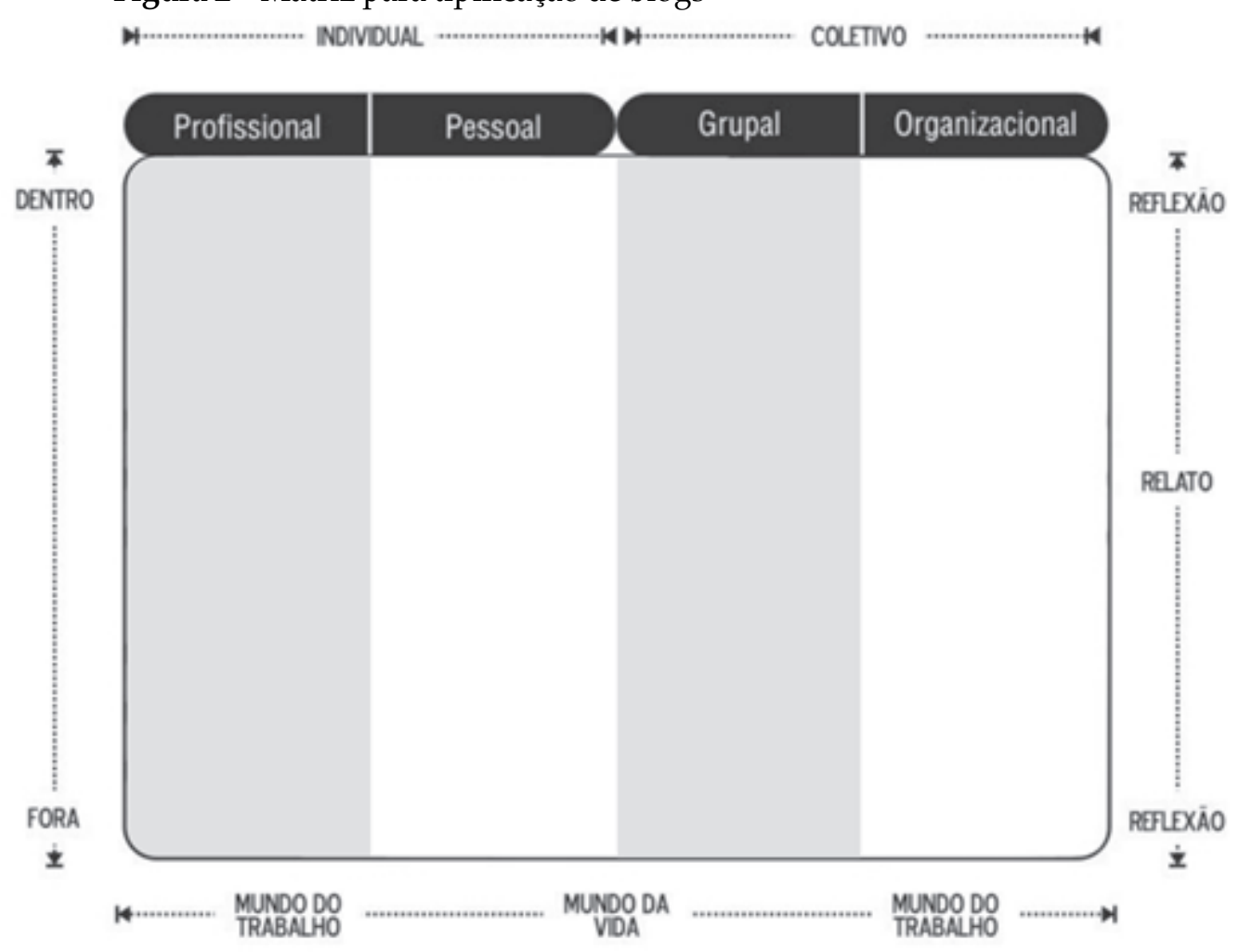

não tenham vínculos com uma instituição midiática, devem ser considerados um exemplo de blog profissional. Para eles, blogar funciona como uma atividade empresarial autônoma. O sustento desses blogueiros provém dos ganhos recebidos por cliques em propaganda veiculadas nas páginas ${ }^{13}$, como também da venda de posts. Nesta última modalidade, o problogger comenta um produto ou serviço para o qual foi pago, podendo ou não informar que trata-se de informação patrocinada.

Os blogs coletivos também apresentam diferenças entre si. Aqueles grupais podem ser escritos por um conjunto de amigos, onde cada um expressa suas opiniões em posts escritos individualmente, mas vinculados a alguns temas acordados. Um blog grupal pode também ser produzido por um grupo de apoio, dando suporte online sobre temas que podem variar de informática a uma determinada doença. $\mathrm{Ou}$ ainda, funcionar como um registro dos avanços e problemas de um grupo de pesquisa ou trabalho, como também de um conjunto de estudantes. Os blogs organizacionais, por outro lado, apresentam funcionamento bastante diferente. Podem ser simplesmente um veículo de divulgação de releases (até mesmo sem serviço de comentários) ou um espaço de interação com clientes e fornecedores.

Como se pode ver, os blogs profissionais e organizacionais tendem ao mundo do trabalho ${ }^{14}$, enquanto os pessoais voltam-se principalmente para o mundo da vida ${ }^{15}$. Blogs grupais tendem para o mundo da vida (por exemplo, um grupo de apoio de pais de portadores de uma certa síndrome), mas podem voltar-se também, ou ao mesmo tempo, para o mundo do trabalho (como a página de um laboratório de pesquisa). A reflexão sobre o mundo da vida tem um impacto identitário importante, como é freqüentemente destacado em estudos sobre blogs pessoais. Quanto aos blog profissionais, pode-se dizer que a atividade de um jornalista no blog que mantém em um portal, conforme exemplo anterior, pode refletir e retroalimentar como ele se vê e como se mostra. De toda forma, um blog jornalístico (que remedia o colunismo em jornais) não tem como objetivo, salvo raras exceções, tratar da vida do autor. No outro extremo, contudo, é difícil encaminhar uma discussão sobre impacto identitário em blogs organizacionais. Levando em conta os exemplos citados, muitos deles são produzidos em tom impessoal, informando decisões formais, podendo inclusive não ser lidos pela maior parte dos funcionários da organização.

Enfim, é preciso comentar que os posts de um blog podem variar entre o relato (como um release, a descrição do enredo de um filme, a sugestão de um link ou até mesmo a simples cópia de um texto publicado alhures) e um texto reflexivo (como a crítica de um filme, avaliação de um software, reflexão sobre uma situação vivida). Além disso, o conteúdo pode ser criado com um olhar que volta-se para fora (para o governo federal, os lançamentos da indústria de informática, para o Campeonato Brasileiro, etc.) ou para dentro (sobre a família e amigos, um projeto próprio do indivíduo ou organização, etc.). Enquanto a compreensão do primeiro movimento em blogs pessoais não parece causar maiores dificuldades, 
vale citar alguns exemplos sobre essa circunstância em blogs coletivos. Estudantes que escrevem sobre as dúvidas e certezas temporárias sobre um trabalho conjunto em um ambiente de educação a distância, podem refletir com o educador sobre o próprio processo construtivo. A equipe de desenvolvimento de um novo produto, que registra e discute o processo na intranet, utiliza o meio de forma bastante distinta de outro blog da mesma empresa direcionado para a imprensa e consumidores. Uma instituição financeira de capital aberto que publica relatos de seu desempenho em um blog, voltado para atuais e potenciais acionistas, também representa um movimento para dentro.

A figura $2^{16}$ ilustra graficamente as dimensões propostas para um estudo de blogs. A parte central da matriz abaixo é destinada para a identificação dos exemplares em análise.

\section{Considerações finais sobre a matriz}

Este artigo buscou discutir a grande variedade de usos de blogs/programa, criticar as generalizações sobre blogs/texto e as visões românticas e normativas sobre a blogosfera. A partir disso, e tendo em vista a limitação de algumas tipologias, apresentou-se uma proposta para o estudo de blogs.

A matriz aqui desenvolvida pode ser usada para a distinção, por exemplo, de blogs em um portal (muitas vezes chamado de "condomínio de blogs"). Para este fim, o título de cada blog deve ser posicionado no interior da matriz em virtude da análise dos mesmos segundo as dimensões detalhadas anteriormente. A matriz para a tipificação de blogs pode também contribuir para o apontamento dos diferentes usos e/ou gêneros desses meios digitais.

No sentido de padronizar-se o uso deste método, propõe-se que a denominação de cada blog ou gênero seja marcado no interior da matriz com um ponto ou círculo, sendo que a sua posição relativa (em qual coluna, para cima ou para baixo, esquerda ou direita) deve ser determinada em virtude das dimensões descritas na parte externa do quadrado central. Finalmente, sugere-se que a inscrição [Privado] seja posicionada abaixo do título ou tipo do blog quando este não tiver caráter público.

Espera-se que as dimensões descritas e representadas graficamente na matriz possam contribuir para o estudo da blogosfera, ultrapassando pré-concepções e generalizações, à medida que chamam a atenção para as peculiaridades de cada situação. Sabe-se que diante de sua operacionalização em diferentes contextos ela precisará receber aperfeiçoamentos, que poderão ampliar o seu alcance mamecos

\section{NOTAS}

1. Veja por exemplo o livro "Blog: comunicação e escrita íntima na internet", de Denize Schittine.

2. No original: "The blog is not a closed world, but part of a larger communication space in which diverse media, and face to face communication, may be brought to bear. Blogs, then, are unlike private diaries, being completely social in nature".

3. Em uma charge, representar alguém conhecido por suas ironias como uma hiena poderia tanto ilustrar sua risada quanto criticá-lo como sendo sorrateiro e perigoso!

4. apud Granieri (2006, p.30).

5. Em trabalhos anteriores (Primo e Smaniotto, 2006a, 2006b) busquei demonstrar as dificuldades e métodos desse tipo de estudo, como também apontar procedimentos para a avaliação dos processos relacionais na blogosfera (Primo, 2007a, 2007b, 2007c).

6. A visão normativa, muitas vezes, parte do modelo jornalístico como padrão geral a ser seguido. Contudo, apenas os blogs jornalísticos (que já escapavam das visões essencialistas do que seriam blogs: confessionais, despreocupados, etc.) podem responder à demanda por valores jornalísticos..

7. No original: "Blogging provides the first adequate toolset for enabling executives and businesspeople to get their messages out directly to their audiences - and to hear back from them, something that does not happen through the media or other relay mechanisms"

8 http://blog.orkut.com/

9. Segundo estatística relatadas por Keen (2007), 56\% da blogosfera é hoje composta por splogs, que despejam 900 mil posts por dia na blogosfera.

10. No Brasil, o termo "flog" é também uma forma abreviada para fotolog.

11. http://payperpost.com/bloggers/marketplace.html [acesso em 22/01/2008.

12. E de fato servem de inspiração inicial para a proposta de estudo que será aqui apresentada.

13. Blogs pessoais também podem ser "monetizados", através da simples incorporação de links patrocinados, como o Google AdSense. Contudo, trata-se apenas de uma possível (talvez, rara) renda extra. Para um pro-blogger, o blog tem como principal objetivo o seu sustento.

14. A oposição que aqui se faz entre mundo do trabalho e mundo da vida é apenas didática, já que o trabalho, claro, faz parte da vida. O que se chama nesta propos de mundo da vida são os relacionamentos pessoais, 
a intimidade, os processos de lazer e diversão, etc.

15. O autor de um blog pessoal pode, claro, escrever sobre o próprio trabalho, mas seu foco principal e o tom da reflexão é diferente do adotado em um blog profissional.

16. Agradeço Elisa Höerle, bolsista de iniciação científica CNPq, pelo desenho da matriz.

\section{REFERÊNCIAS}

BOLTER, Jay David. Writing Space: computers, hypertext, and the remediation of print. 2. ed. Mahwah: Lawrence Erlbaum, 2001.

EFIMOVA, Lilia; MOOR, Aldo de. Beyond personal webpublishing: an exploratory study of conversational blogging practices. In: Thirty-eighth Hawaii International Conference on System Sciences, 2005, Havaí. Anais. Havaí, 3-6 Janeiro de 2005.

GRANIERI, Giuseppe. Geração blogue. Lisboa: Presença, 2006.

HERRING, Susan C.; Scheidt, L. A.; Bonus, S.; Wright, E. Weblogs as a bridging genre. Information Technology \& People, v. 18, n. 2, p. 142-171, 2005.

HERRING, Susan C. Interactional Coherence in CMC. In: Thirty-second Hawaii International Conference on System Sciences, 1999, Havaí. Anais. Havaí, 1999.

KEEN, Andrew. The cult of the amateur : how today's internet is killing our culture. New York: Doubleday/Currency, 2007.

KRISHNAMURTHY, S. (2002). The Multidimensionality of Blog Conversations: The Virtual Enactment of September 11. In Maastricht, The Netherlands: Internet Research 3.0.

NONAKA, Ikujiro; TAKEUCHI, Hirotaka. Criação de conhecimento na empresa. Rio de Janeiro: Campus, 1997.

PRIMO, Alex ; SMANIOTTO, Ana Maria Reczek . Blogs como espaços de conversação: interações conversacionais na comunidade de blogs insanus. e Compos, v. 1, n. 5, p. 1-21, 2006 a.

PRIMO, Alex; SMANIOTTO, Ana Maria Reczek. Comunidades de blogs e espaços conversacionais. Prisma.com, v. 3, p. 1-15, 2006 b.

PRIMO, Alex. Avaliação qualitativa de interações em redes sociais: Relacionamentos no blog Martelada.
In: XXX Congresso Brasileiro de Ciências da Comunicação, 2007. Anais. Santos: Intercom, 2007.

PRIMO, Alex . Interação mediada por computador: comunicação, cibercultura, cognição. Porto Alegre: Sulina, 2007a.

PRIMO, Alex . O aspecto relacional das interações na Web 2.0. E-Compós (Brasília), v. 9, p. 1-21, 2007b.

PRIMO, Alex. Avaliação qualitativa de interações em redes sociais: Relacionamentos no blog Martelada. Comunicação, Mídia e Consumo (São Paulo), v. 4, p. 137-158, 2007c.

SCHITTINE, Denise. Blog: comunicação e escrita íntima na internet. Rio de Janeiro: Civilização Brasileira, 2004.

SCOBLE, Robert; ISRAEL, Shel. Naked Conversations: How Blogs are Changing the Way Businesses Talk with Customers. Hoboken: Wiley, 2006. 